Artículo de investigación.

Cómo citar: L. Velandia, J. De Plaza, y D. Pulgarín "Análisis comparativo del componente administrativo y de los procesos de desinfección utilizados en dos plantas de tratamiento de agua potable", Inventum, vol. 14 , no. 27 , pp. 78-88. doi: 10.26620/uniminuto.inventum.14.27.2019.78-88

Editorial: Corporación Universitaria Minuto de Dios - UNIMINUTO.

ISSN: $1909-2520$

eISSN: $2590-8219$

Fecha de recibido: mayo 01 de 2019 Fecha de aprobado: junio 30 de 2019 Fecha de publicación: septiembre 01 de 2019

Conflicto de intereses: los autores han declarado que no existen intereses en competencia.

\section{Análisis comparativo del componente administrativo y de los procesos de desinfección utilizados en dos plantas de tratamiento de agua potable}

\author{
Comparative analysis of the \\ administrative component and \\ disinfection processes used in two \\ drinking water treatment plants
}

\author{
Análise comparativa do componente \\ administrativo e dos processos de \\ desinfecção utilizados em duas estações \\ de tratamento de água potável
}

Laura Velandia Medina

ivelandia53@ucatolica.edu.co

Universidad Católica de Colombia, Colombia.

Juan Sebastián De Plaza

jsdeplaza@ucatolica.edu.co

Universidad Católica de Colombia, Colombia.

Diego Alejandro Pulgarín

dapulgarin@ucatolica.edu.co

Universidad Católica de Colombia, Colombia.

\begin{abstract}
Resumen
Este artículo contiene el análisis comparativo realizado entre dos plantas de tratamiento de agua potable (PTAP), una que abastece de agua a una parte de Bogotá, Colombia y otra en Boston, Estado Unidos de América (EE. UU.). El análisis se enfoca en tres aspectos: el tratamiento implementado en el agua que ingresa a las PTAP, el desinfectante utilizado en las plantas y el modelo administrativo utilizado en cada país. De acuerdo con estudios desarrollados en la Carroll Water Treatment Plant (CWTP), al implementar el sistema de desinfección por ozonización se obtienen cambios notables y considerables en las características del agua, su sabor y color, un aumento en la inactivación de patógenos, así como una dramática reducción en los subproductos de la desinfección. Por otra parte, contar con varias entidades que intervengan en la administración financiera del recurso hídrico proporciona un mejor control y vigilancia de este, como en EE. UU. Asimismo, la prevención de la contaminación del agua parece una directiva de manejo más sabia y prudente que la limpieza de nuestras fuentes de agua en el futuro.
\end{abstract}

Palabras clave: comparación, desinfección, PTAP, agua.

\begin{abstract}
This article contains the comparative analysis conducted between two drinking water treatment plants (PTAP), one that supplies water to a part of the city of Bogotá, Colombia and another to the city of Boston, United States of America (USA). The analysis focuses on three aspects, the treatment implemented in the water that enters the PTAP's, the disinfectant used in the plants and the administrative model used in
\end{abstract}


each country. According to studies carried out at the Carroll Water Treatment Plant (CWTP), when implementing the Ozonation disinfection system, considerable and considerable changes are obtained in the characteristics of the water, its flavor and color, an increase in the inactivation of pathogens, as well as a dramatic reduction in disinfection byproducts. On the other hand, having several entities that intervene in the financial administration of the water resource provides better control and monitoring of it, as in the USA. Likewise, the prevention of water pollution seems a wiser and prudent management directive than the cleaning of our water sources in the future.

Keywords: comparison, disinfection, ptap, water.

\section{Resumo}

Este artigo contém a análise comparativa realizada entre duas estações de tratamento de água potável (PTAP), uma que fornece água para uma parte da cidade de Bogotá, Colômbia e a outra para a cidade de Boston, Estados Unidos da América (EUA). A análise se concentra em três aspectos, o tratamento implementado na água que entra nos PTAP's, o desinfetante usado nas plantas e o modelo administrativo usado em cada país. De acordo com estudos realizados na Estação de Tratamento de Água de Carroll (CWTP), ao implementar o sistema de desinfecção por Ozonação, obtêm-se mudanças notáveis e consideráveis nas características da água, seu sabor e cor, um aumento na inativação de patógenos, bem como uma redução drástica nos subprodutos da desinfecção. Por outro lado, contar com várias entidades que intervêm na administração financeira do recurso hídrico proporciona melhor controle e monitoramento, como nos EUA. Da mesma forma, prevenir a poluição da água parece ser uma diretiva de gerenciamento mais sábia e prudente do que limpar nossas fontes de água no futuro.

Palavras-chave: comparação, desinfecção, ptap, água. 


\section{INTRODUCCIÓN}

El agua pura no existe en la naturaleza, el concepto correcto es el de agua segura y agua potable [1]. El tratamiento que se debe realizar al agua con el fin de obtener su potabilización depende principalmente de la calidad del agua en la fuente de captación. En este sentido, puede requerirse un tratamiento convencional, en el cual se consideran los procesos de: pretratamiento, coagulación, floculación, sedimentación, filtración y desinfección [2], o simplemente puede requerirse una desinfección cuando el agua cruda presenta una buena calidad. El principal problema asociado al agua con una deficiente calidad está relacionado con las enfermedades que esta puede ocasionar. La primera observación registrada de una amplia transmisión de enfermedad por un suministro de agua pública es la de Londres en 1854, donde apareció la epidemia de cólera relacionada con el pozo de la calle Broad [3]. Casos similares se presentaron en Hamburgo, Lausana, Pennsylvania, Massachusetts, Chicago, Illionis, Ashland, Wisconsin, Minnesota, Pittsburg $y$, a principios del siglo XX, en Lincoln, todas asociadas a la contaminación de los suministros de agua [3]. Con el fin de prevenir la proliferación de las enfermedades ligadas al consumo de agua, surgió la necesidad de crear diferentes mecanismos para eliminar las bacterias que causan dichas enfermedades. El cloro es una opción de tratamiento de bajo costo que elimina muchos microorganismos como bacterias y virus [4], la radiación ultravioleta es una técnica que consiste en inactivar los microorganismos con la luz UV como resultado del daño fotoquímico a sus ácidos nucleicos [5] y la desinfección con ozono (ozonización) que es efectiva en la inactivación de patógenos, incluyendo bacterias, protozoarios y virus [6]. Teniendo en cuenta que los sistemas de desinfección con cloro generan unos subproductos que potencialmente pueden afectar la salud de las personas [7], en este estudio, se realiza el análisis comparativo en los componentes técnicos de tratamiento y administrativos, a partir de la visita técnica llevada a cabo en las plantas de tratamiento de agua potable (PTAP) de Tibitoc (Colombia) y la John J. Carroll Water Treatment Plant (CWTP) en Boston (EE. UU.), con el fin de analizar la posibilidad de transferencia tecnológica entre la planta CWTP (EE. UU.) y la planta Tibitoc (Colombia).

\section{DESARROLLO DE CONTENIDOS}

Para el desarrollo de esta investigación, se recolectó la información disponible en libros, artículos, páginas web, entre otros, relacionada con los procesos de desinfección del agua para las PTAP en estudio, en este caso, ozonización, luz ultra violeta (UV), cloro y el componente administrativo de los sistemas de abastecimiento, desde su captación hasta la distribución final en las redes de acueducto.

Seguidamente, se visitó la PTAP Tibitoc, localizada en Tocancipá, Cundinamarca, y la John J. Carroll Water Treatment Plant (CWTP) localizada en Marlborough, Massachusetts.

Finalmente, se realizó el análisis comparativo de los métodos empleados para desinfectar el agua en las plantas de tratamiento en estudio, así como, la protección ambiental para cada embalse de abastecimiento en las plantas estudiadas; de la misma manera, se identificaron las diferencias entre los modelos administrativos, y se estableció si existe la necesidad de modificar alguno de los aspectos que se relacionan en este análisis.

\section{A. Descripción de la planta de Tibitoc}

En la inspección de campo realizada a la Planta de Tratamiento Tibitoc, se pudo identificar que utiliza un sistema de tratamiento convencional tal como se muestra en la figura 1. 
Figura 1. Procesos de tratamiento PTAP Tibitoc

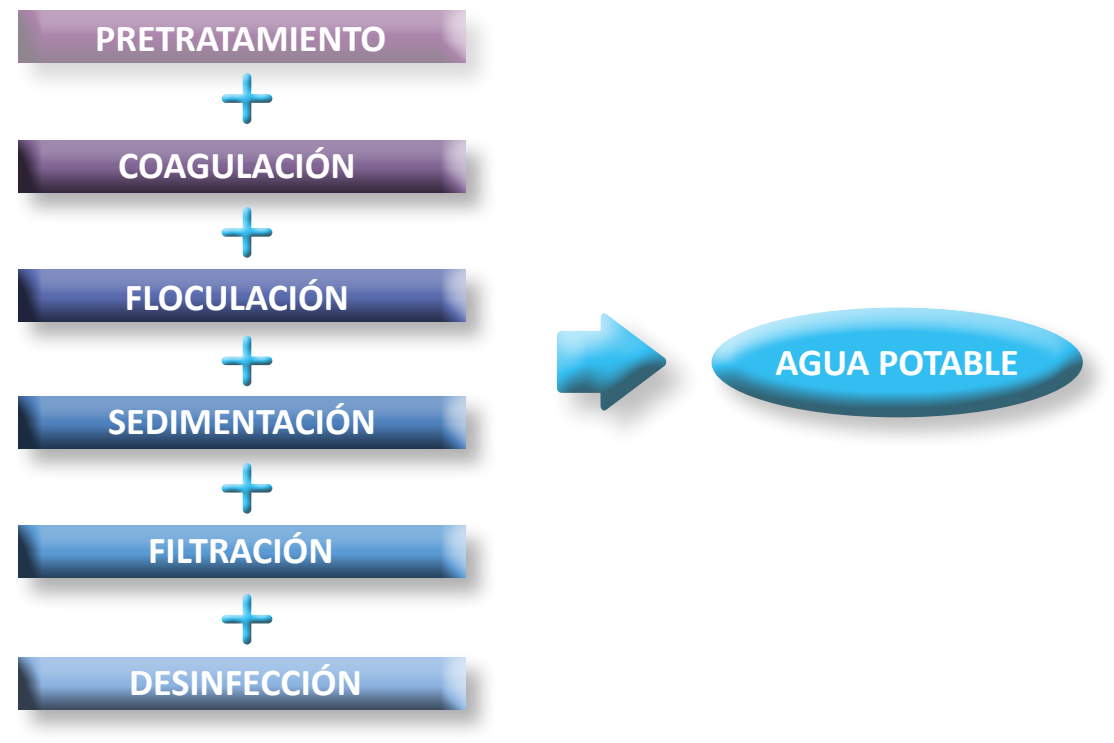

Fuente: elaboración propia.

De acuerdo con dicha clasificación, la fuente de agua para la PTAP de Tibitoc es considerada una fuente deficiente o muy deficiente, de ahí que realice proceso de presedimentación, coagulación, floculación, sedimentación, filtración y desinfección. Si las características del agua antes de ingresar a la PTAP mejoraran a tal grado que cumplieran los parámetros de fuente aceptable, solo sería necesario realizar el proceso de desinfección y estabilización, caso de la CWTP.

Es importante mencionar que la Empresa de Acueducto, Alcantarillado y Aseo de Bogotá (EAABESP) realiza la gestión integral del recurso hídrico para la ciudad, iniciando con la conservación del sistema hídrico, de allí se realiza la producción de agua potable con la captación en las fuentes de agua superficial, pasando por las plantas de tratamiento (PTAP) y luego el transporte y la conducción a través del sistema matriz de acueducto para terminar con la distribución a través de las redes menores de acueducto, esto permite asegurar el suministro de agua potable en las viviendas, industrias e instituciones y comercializadores del servicio de agua en bloque [1].

Luego de ser utilizado, el recurso es recogido y separado donde sea posible. Las aguas lluvias y residuales son recolectadas a través de las redes locales y secundarias de alcantarillado, para luego ser transportadas por el sistema troncal pluvial a los cuerpos de agua y a las aguas residuales de la parte norte de la ciudad, por lo que se llevan a través de la cuenca del río Salitre hasta la planta de tratamiento de aguas residuales (PTAR) El Salitre y después de tratadas, se disponen en la fuente receptora el río Bogotá [8].

De este mismo modo, la Empresa de Acueducto, Alcantarillado y Aseo de Bogotá es la encargada de facturar el servicio de forma tal que el consumo sea el elemento principal del precio que se cobre al suscriptor o usuario, de acuerdo con los parámetros señalados por la Ley 142 de 1994 o por las autoridades competentes [9].

En Colombia existe la Resolución 2115 de 2007, que señala las características, instrumentos básicos y frecuencias del sistema de control y vigilancia para la calidad del agua para consumo humano. Por lo tanto, establece el índice de riesgo de calidad del agua (IRCA), indicador utilizado para evaluar la calidad del agua de consumo, el cual se genera a partir de la información recopilada con las muestras de vigilancia y control. 
Adicionalmente, mediante el Decreto 1575 de 2007 se establece que se debe coordinar la identificación de los factores de riesgo y las características físicas, químicas y microbiológicas de las fuentes de agua aferentes a las captaciones de acueducto que puedan afectar la salud humana, con ello se contribuye a las acciones de inspección, vigilancia y control por parte de las autoridades competentes.

\section{B. Descripción de la PTAP Jhon J. Carroll}

En la inspección de campo realizada a la John J. Carroll Treatment Plant (CWTP), se encontró que allí se realiza un proceso avanzado para el tratamiento del agua que incluye solamente la desinfección, es decir, no necesita realizar procesos de aireación, coagulación, floculación, sedimentación ni filtración, porque la calidad del agua antes de ingresar a la planta es elevada (ver tabla 1).

Tabla 1. Sistema de tratamiento en la CWTP

\begin{tabular}{|c|c|c|c|c|c|c|c|}
\hline \multicolumn{7}{|c|}{ DESINFECCIÓN } \\
\hline Ozono & $\begin{array}{c}\text { Bisulfato } \\
\text { de sodio }\end{array}$ & Luz UV & $\begin{array}{c}\text { Hipoclorito de } \\
\text { Sodio }\end{array}$ & $\begin{array}{c}\text { Ácido hidrofluoro } \\
\text { silicio de sodio }\end{array}$ & $\begin{array}{c}\text { Amoniaco } \\
\text { acuoso }\end{array}$ & $\begin{array}{c}\text { Carbonato } \\
\text { de sodio }\end{array}$ & $\begin{array}{c}\text { Dióxido de } \\
\text { carbono }\end{array}$ \\
\hline
\end{tabular}

Fuente: elaboración propia.

La cantidad de agua tratada en la CWTP es de 9,2 $\mathrm{m}^{3} / \mathrm{s}$, aunque cuenta con la capacidad de tratar $17,74 \mathrm{~m}^{3} / \mathrm{s}$, es decir, 405 millones de galones por día.

Como se sabe, una cuenca es el área total que drena directamente a través de la tierra e indirectamente a través de las aguas subterráneas, a un arroyo, río, estanque o embalse en particular. En Massachusetts, se encargan de proteger las cuencas hidrográficas porque todas las actividades dentro de ellas tienen impactos en la calidad del agua. La protección de la fuente está guiada por el programa de protección de cuencas hidrográficas DCR's Division of Water Supply Protection (DWSP).

Según la MWRA, la mejor manera de suministrar agua limpia y segura es comenzar con agua de alta calidad. Desde la década de 1870, los planificadores han buscado fuentes de agua relativamente prístinas y protegidas para el área metropolitana de Boston, que requerirían un tratamiento de agua mínimo. Históricamente, se han asegurado reservorios cada vez más grandes y distantes en el centro y el oeste de Massachusetts para suministrar tanto la cantidad como la calidad del agua necesaria. Como resultado, MWRA heredó en 1985 un sistema de agua cuyas fuentes (Wachusett, Quabbin y Ware River) son las menos contaminadas disponibles y requieren un nivel mínimo de tratamiento: desinfección y control de corrosión [10].
La Autoridad de Recursos Hídricos de Massachusetts (MWRA) y el Departamento de Conservación y Recreación (DCR) administran conjuntamente el Sistema de Agua Metropolitano de Boston. La MWRA proporciona tratamiento y distribución de agua potable a 48 comunidades en el área metropolitana, incluida Boston. El DCR administra los terrenos adyacentes a los reservorios de origen y es responsable de mantener los reservorios libres de contaminación de la calidad del agua en la mayor medida posible.

Con respecto al proceso de desinfección del agua en la CWTP, allí se determinó utilizar el ozono como desinfectante primario porque proporciona una mejor desinfección que el cloro solo, y también porque reduce la cantidad de subproductos de desinfección potencialmente dañinos. Sin embargo, a partir de 2014, también se utiliza luz ultravioleta, porque en enero de 2006 la "Regla de tratamiento de aguas superficiales mejoradas a largo plazo 2", desarrollada por la EPA (U.S. Environmental Protection Agency), establece que todos los sistemas de agua sin filtrar deben implementar un tratamiento adicional dado que son sistemas de mayor riesgo, y la desinfección UV es una opción.

De acuerdo a estudios desarrollados en la planta de tratamiento John J. Carroll, al implementar el sistema de desinfección por ozonización se obtuvieron cambios notables y considerables en 
las características del agua, su sabor y color, un aumento en la inactivación de patógenos, así como una dramática reducción en los subproductos de la desinfección (ver figura 2). Por lo que se convirtió en el desinfectante primario en dicha planta, como se muestra a continuación [11].

Figura 2. Subproductos de la cloración en la CWTP

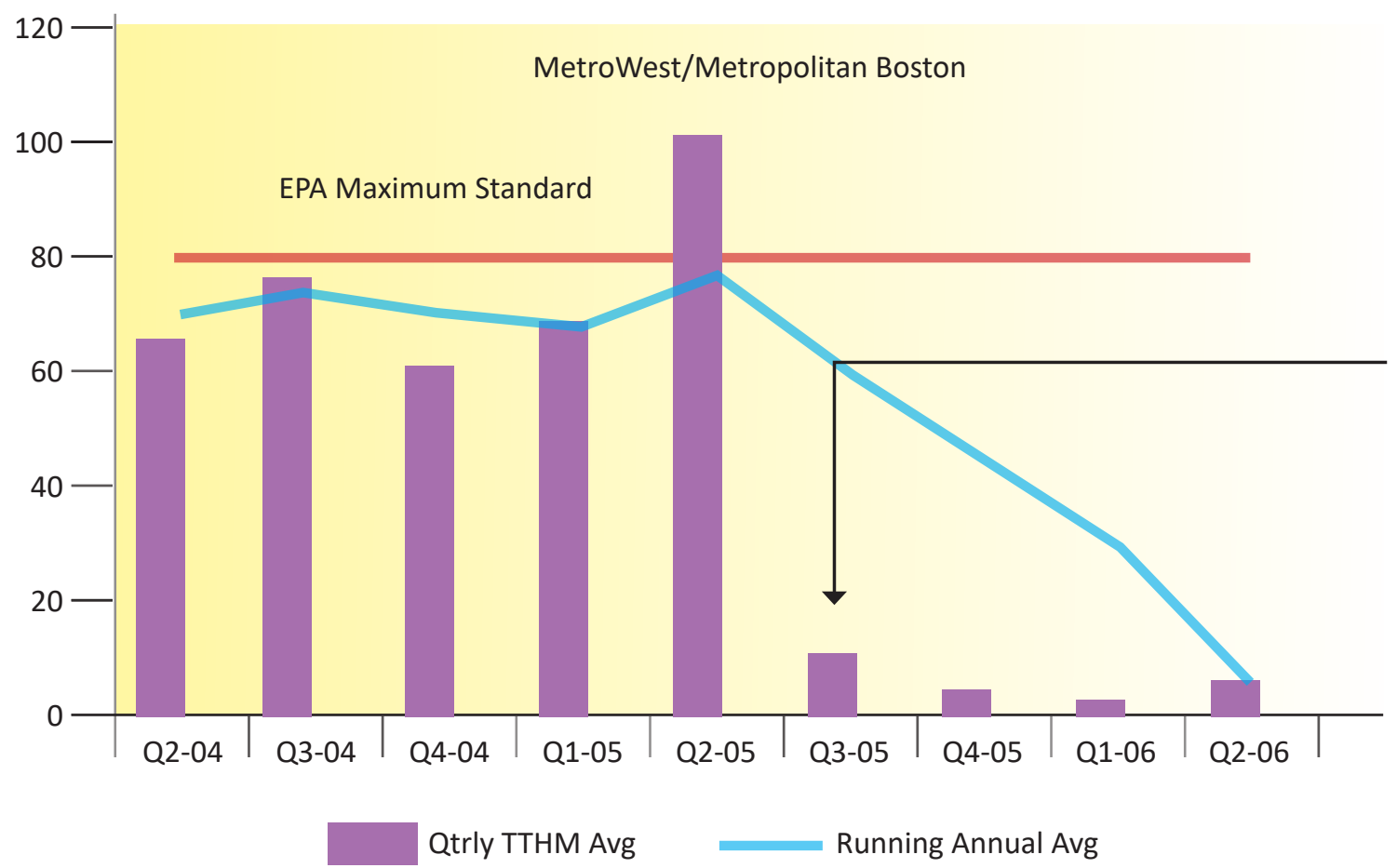

Fuente: elaboración propia.

Otro aspecto importante que se determinó gracias a la visita en la CWTP es que para tener agua de alta calidad antes de ingresar a la planta, se debe garantizar la protección y cuidado del agua desde la fuente, ya sea implementando una normativa de estricto cumplimiento que proteja el agua contra los contaminantes naturales y artificiales, productos químicos desechados de manera inadecuada; desechos animales; pesticidas, amenazas humanas; residuos inyectados bajo tierra y sustancias naturales que pueden contaminarla, como en Estado Unidos, donde existe una ley denominada The Safe Drinking Water Act (SDWA), la cual se enfoca en garantizar la protección del agua mucho antes de ingresar a la WTP.

De allí, para garantizar que el agua potable sea segura, SDWAestablece múltiples barreras contra la contaminación, estas barreras incluyen protección del agua de la fuente, tratamiento, integridad del sistema de distribución e información pública. Lo que permite inferir, que en Estados Unidos los componentes esenciales del agua potable segura incluyen protección y prevención, por lo que los estados y los proveedores de agua deben realizar evaluaciones de las fuentes de agua para ver dónde pueden ser vulnerables a la contaminación. De la misma forma, según la SDWA los sistemas de agua también pueden adoptar voluntariamente programas para proteger su cuenca o pozo, y los estados pueden usar las autoridades legales de otras leyes para prevenir la contaminación [12].

Si bien, la Regla Federal de Tratamiento de Agua de Superficie (SWTR) requiere la filtración de todos los suministros de agua de superficie, a menos 
que se cumplan numerosos criterios, incluido el desarrollo y la implementación de un plan detallado de protección de cuencas, la División de Protección de Suministro de Agua y la MWRA tienen una exención conjunta del requisito de filtración y continúan administrando agresivamente la cuenca para mantener esta exención [6].

El muestreo del agua y las inspecciones de campo, ayudan a identificar los afluentes con problemas de calidad del agua, a la implementación del plan de protección de cuencas más reciente y a garantizar el cumplimiento de los criterios estatales y federales de calidad del agua para las fuentes públicas de suministro de agua potable. El monitoreo de bacterias y nutrientes del reservorio y afluentes proporciona una indicación de la calidad sanitaria y ayuda a proteger la salud pública. El personal de la División también toma muestras para comprender mejor las respuestas del reservorio y sus afluentes a una variedad de insumos físicos, químicos y biológicos, y para evaluar la salud ecológica del reservorio y la cuenca [13].

En ese sentido, los afluentes y reservorios de cuencas hidrográficas comprenden los dos componentes básicos del sistema de suministro de agua. Cada componente requiere un programa especializado de monitoreo de actividades y equipos adaptados a sus características únicas y entornos ambientales.

Otro aspecto importante que se encontró por medio de la visita en CWTP es que el Gobierno de Massachusetts estableció un programa de protección del suministro de agua administrado por un fideicomiso de protección del suministro de agua. El fideicomiso proporciona un mecanismo más eficiente para que MWRA financie la Oficina de Administración de Cuencas. Los contribuyentes de MWRA financian en su totalidad el presupuesto anual de $\$ 30$ millones USD de la Oficina de Administración de Cuencas Hidrográficas.

Por su parte, la Comisión de Agua y Alcantarillado de Boston (BWSC, por sus siglas en inglés) administra el sistema más grande y antiguo de su tipo en Nueva Inglaterra (región de los Estados Unidos integrada por seis estados, incluyendo Massachusetts), y brinda servicios de agua potable y alcantarillado a más de un millón de personas diariamente.

La Autoridad de Recursos Hídricos de Massachusetts (MWRA) es el proveedor mayorista de servicios de agua y alcantarillado para 61 comunidades en el área metropolitana de Boston. Esta entidad le vende los servicios de tratamiento de agua potable y aguas residuales a La Comisión de Agua y Alcantarillado de Boston, siendo el mayor cliente individual de MWRA para servicios de agua y alcantarillado, y los cargos de MWRA representan el componente individual más grande de los gastos operativos de BWSC, los cuales se encargan de cobrar el servicio de agua potable y alcantarillado en la ciudad [14].

\section{III.RESULTADOS Y DISCUSIÓN}

En las tablas 2, 3 y 4 se pueden observar las características del agua que ingresa a las PTAP.

Tabla 2. Características de las fuentes de captación

\begin{tabular}{|c|c|c|c|c|c|c|}
\hline \multirow{2}{*}{ Embalse } & \multicolumn{5}{|c|}{ Concentración de los parámetros registrados } \\
\cline { 2 - 7 } & Fósforo & Amoniaco & Nitrato & NTK & UV254 \\
\hline & $\mathrm{mg} / \mathrm{L}$ & $\mathrm{mg} / \mathrm{L}$ & $\mathrm{mg} / \mathrm{L}$ & $\mathrm{mg} / \mathrm{L}$ & $\mathrm{mg} / \mathrm{L}$ \\
\hline Wachusett & 0,008 & 0,01 & 0,049 & 0,155 & 0,073 \\
\hline Quabbin & 0,006 & 0,007 & 0,009 & 0,294 & 0,032 \\
\hline Sisga & - & 0,7 & 0,1145 & - & - \\
\hline Tominé & - & - & 15,995 & - & - \\
\hline Neusa & - & 0,7 & 0,305 & - & - \\
\hline
\end{tabular}

Fuente: elaboración propia 
Tabla 3. Características de las fuentes de captación

\begin{tabular}{|c|c|c|c|c|c|c|}
\hline \multirow{2}{*}{ Embalse } & \multicolumn{5}{|c|}{ Concentración de los parámetros registrados } \\
\cline { 2 - 7 } & Sílice & Alcalinidad & Turbiedad & Conductividad & $\mathrm{pH}$ \\
\hline & $\mathrm{mg} / \mathrm{L}$ & $\mathrm{mg} / \mathrm{L}$ & $\mathrm{mg} / \mathrm{L}$ & $\mathrm{mg} / \mathrm{L}$ & $\mathrm{mg} / \mathrm{L}$ \\
\hline Wachusett & 2,49 & 6,51 & $0,12-70,50$ & $129-194$ & $.6-7$ \\
\hline Quabbin & 1,78 & 5,72 & $0,23-1,13$ & $40,6-71,2$ & $4,8-7,8$ \\
\hline Sisga & - & - & - & 25,7 & 7 \\
\hline Tominé & - & - & - & 53,7 & 7,01 \\
\hline Neusa & - & - & - & 64,4 & 7,2 \\
\hline
\end{tabular}

Fuente: elaboración propia.

Tabla 4. Características de las fuentes de captación

\begin{tabular}{|c|c|c|c|c|c|}
\hline \multirow{3}{*}{ Embalse } & \multicolumn{5}{|c|}{ Concentración de los parámetros registrados } \\
\hline & $\begin{array}{l}\text { Oxígeno } \\
\text { disuelto }\end{array}$ & $\begin{array}{c}\text { Sólidos } \\
\text { suspendidos totales }\end{array}$ & $\begin{array}{l}\text { Coliformes } \\
\text { fecales }\end{array}$ & E. coli & $\begin{array}{l}\text { Coliformes } \\
\text { totales }\end{array}$ \\
\hline & $\mathrm{mg} / \mathrm{L}$ & $\mathrm{mg} / \mathrm{L}$ & $($ CFU/100 ml) & $($ CFU/100 ml) & $($ CFU/100 ml) \\
\hline Wachusett & $>4,5$ & - & {$[<1-32]$} & {$[<1-95] 4$} & - \\
\hline Quabbin & 6,0 & - & [1-6] & 20 & [10-24200] \\
\hline Sisga & 5,8 & 5,7 & - & 100 & 2100 \\
\hline Tominé & 6,0 & 5,3 & - & 100 & 2680 \\
\hline Neusa & 6,7 & 6,3 & - & 100 & 10950 \\
\hline
\end{tabular}

Fuente: elaboración propia.

Al revisar la normativa que implementa cada una de las ciudades de acuerdo al país, se encuentra que los parámetros que se deben medir y monitorear en las fuentes de captación en su mayoría son los mismos, pero en los informes de calidad que reporta la CAR, entidad competente para los embalses Sisga, Neusa y Tominé, no registra la información de varios parámetros como se muestra en las tablas 2, 3 y 4, por ende, solo se puede realizar la comparación de los parámetros que tienen valores.

Al realizar la comparación de los parámetros de calidad de agua de las anteriores tablas, se puede señalar que a pesar de que algunos parámetros (oxígeno disuelto y coliformes totales), presentan rangos de valores muy similares o dispersos entre los embalses, en general los embalses de USA presentan mejores condiciones de calidad (nitrato, amoniaco y bacterias $E$. coli), sin pasar por alto que en el los depósitos de agua de Colombia ciertas variables demuestran mejores condiciones ( $\mathrm{pH}$ y conductividad eléctrica).

Es importante mencionar, que como se evidencia en las tablas 2, 3 y 4, el informe de calidad del agua de los embalses Wachusett y Quabbin presenta los resultados de los parámetros de calidad de cada punto de monitoreo con sus respectivos análisis, no solo de manera descriptiva, además de que las variables utilizadas para definir la calidad del agua en los embalses de USA no son las mismas en Colombia. En contraste, el informe de calidad hídrica que realiza la Corporación Autónoma 
Regional (CAR) se limita en describir los resultados de cada parámetro medido e indicar el valor del índice de calidad de agua obtenido en cada punto de monitoreo.

Como se mencionó anteriormente, la protección de la fuente en Massachusetts está guiada por el programa de protección de cuencas hidrográficas DWSP (DCR's Division of Water Supply Protection). En Colombia las entidades nacionales ejecutan acciones para mejorar el monitoreo que realiza el Instituto de Hidrología, Meteorología y Estudios Ambientales (IDEAM) a las principales cuencas del país y apoyar el monitoreo de las autoridades ambientales regionales como la CAR en su Dirección de Monitoreo, Modelamiento y Laboratorio Ambiental.

En la CWTP, el tratamiento del agua que ingresa se realiza directamente con desinfección, porque se garantiza la protección del agua desde su fuente y por ende, su calidad antes de llegar a la WTP. Por el contrario, la PTAP Tibitoc trata el agua iniciando con el proceso de presedimentación, ya que según las características del agua no se puede realizar filtración directa ni mucho menos sólo el proceso de desinfección [15].

En ese sentido, de acuerdo al Decreto 1575 de 2007, se establece como desinfectante predeterminado el cloro, sin embargo, se hace la aclaración de que cuando se utiliza un desinfectante diferente al cloro o cualquiera de las formulaciones o sustancias que utilicen compuestos distintos para desinfectar el agua para consumo humano, los valores aceptables para el residual correspondiente u otras consideraciones al respecto, serán los reconocidos por la Organización Mundial de la Salud y adoptados por el Ministerio de la Protección Social, quien tendrá en cuenta el respectivo concepto toxicológico del producto para expedir el concepto técnico.

Como ya se evidenció, la CWTP realiza el procedimiento de desinfección utilizando ozono, ya que se considera que este genera menos subproductos, y luz UV porque en dosis rentables inactiva de manera efectiva patógenos comunes como Cryptosporidium, Giardia y la mayoría de los patógenos bacterianos. En contraste, la PTAP Tibitoc realiza la desinfección con cloro, se aclara que en los resultados de calidad del agua potabilizada de SIVICAP que suministra el Ministerio de Tecnologías de la Información y las Comunicaciones, no se registran datos de concentración de éstos patógenos, Cryptosporidium y Giardia, los cuales han demostrado ser resistentes al cloro [16].

En este sentido, según la Resolución 2115 de 2007 Art. 11, dentro de las características microbiológicas del agua para consumo humano, se incluye que el valor aceptable para Giardia es de cero (0) quistes y para Cryptosporidium debe ser de cero (0) quistes por volumen fijado según la metodología aplicada.

Además, de acuerdo al Art. 22, se menciona que dentro del mapa de riesgo se debe estudiar la presencia de Giardia y Cryptosporidium, así como otros microorganismos en la fuente con el fin de determinar si es necesario realizar el control en el agua para consumo humano. Si se determina que es necesario el control, el mapa de riesgo deberá determinar la frecuencia mínima y el número mínimo de muestras a analizar por cada frecuencia. De manera que se debe hacer el monitoreo de estos parásitos desde la fuente de captación hasta el momento de distribuir el agua a los suscriptores del servicio.

Otro aspecto que se debe comparar es el manejo administrativo que se hace al recurso, como ya se mencionó, la Empresa de Acueducto y Alcantarillado y Aseo de Bogotá, la cual produce y suministra el agua potable a la ciudad de Bogotá, es la misma que realiza el cobro del servicio a los usuarios, mientras que, en Boston, la empresa que realiza el tratamiento del agua (MWRA) no es la misma que cobra a los residentes de la ciudad. BWSC compra servicios de tratamiento de agua tratada y aguas residuales de MWRA y los proporciona posteriormente a la comunidad.

Por otra parte, como ya se mencionó, el proceso de desinfección en la John J. Carroll WTP incluye los pasos que se muestran en la figura 2, desde el recorrido del agua por los generadores de ozono para lograr la inactivación de patógenos, hasta la aplicación de químicos como dióxido de carbono en el edificio de postratamiento para ajustar el $\mathrm{pH}$ al final. En contraste, en la PTAP Tibitoc el proceso de desinfección consiste en aplicar cloro libre y combinado acorde con la presencia de materia orgánica, manganeso, hierro y agentes patógenos.

La concentración de cloro libre oscila entre $1,7-1,8 \mathrm{mg} / \mathrm{L}$, mientras que el cloro combinado con yoduro de potasio entre 0,1-0,2 mg/L. De manera que, al utilizar estos rangos de concentración de 
cloro, se pretende no generar la formación de subproductos tales como trihalometanos y ácidos acéticos halogenados. En caso de ser así, la PTAP tiene como alternativa de oxidación de estos compuestos, realizar el proceso de aireación.

\section{CONCLUSIONES}

Por muchas razones se podría preferir la implementación de un método sobre otro. En Estados Unidos, dado que solo se requiere efectuar el proceso de desinfección, se prefiere primordialmente la técnica que realiza de manera más eficiente la desinfección y es más avanzada, aunque no sea la más económica, el Ozono, sin olvidar la luz ultravioleta, la cual les garantiza una mayor inactivación de patógenos como Giardia y Cryptosporidium, e implementan una pequeña dosis de cloro para mantener un efecto residual duradero al transportar el agua por la red de distribución.

En Colombia, solamente se utiliza cloro para el proceso de desinfección debido a que es el método más económico y popular en el mundo. Se debe reconocer que antes de llegar a la desinfección en la PTAP, se realizan procesos de pre sedimentación, coagulación, floculación, sedimentación y filtración, los cuales mejoran las características del agua, pero de igual manera requieren de mantenimiento, supervisión, entre otros trabajos, y al momento de la creación de la PTAP al ser tantos procesos que se debían realizar, se debió considerar un método eficiente pero económico.

Adicionalmente, hay que mencionar que la PTAP Tibitoc entró en funcionamiento por primera vez en 1958 con una capacidad inicial de 3,5 metros cúbicos por segundo, mientras que la John J. Carroll WTP, localizada en Massachusetts inicio su funcionamiento en 2005, medio siglo después; sumándole a ese hecho que Estados Unidos en ese entonces ya era reconocido como una potencia mundial, mientras que Colombia es un país tercermundista, con condiciones completamente diferentes.

En este orden de ideas, como propuesta de transferencia tecnológica, más que la implementación de desinfección con ozono y luz ultravioleta para inactivar y controlar de manera más eficiente los patógenos Cryptosporidium y Giardia en la PTAP Tibitoc, se considera que es más significativo transferir los métodos, leyes y regulaciones implementados en Estados Unidos, porque garantizan alta calidad de agua desde las fuentes, de manera que en las PTAP solo se requiere realizar el tratamiento de desinfección al agua, es decir, ahorrarse los procesos de pretratamiento, coagulación, floculación, sedimentación y filtración, y de esta manera, también se puede optar por implementar el método más eficiente en desinfección e inclusive avanzado.

Con todo, mantener fuentes de agua potable limpias y seguras se está convirtiendo cada vez más en una prioridad debido a la contaminación global. Los medios para alcanzar y mantener fuentes de agua potable limpias requieren políticas efectivas que identifiquen, documenten y reduzcan los riesgos de las cuencas hidrográficas. Estos riesgos están definidos por su impacto potencial en la salud humana. La salud y el riesgo están, por lo tanto, indeleblemente vinculados porque en parte se definen entre sí [17].

En última instancia, la gestión del agua potable debe basarse en una ciencia y una política sólidas, una instrumentación de política efectiva y una comprensión clara del riesgo. Lo esencial de la calidad del agua potable actual se centra en el producto final, sin embargo, la calidad del agua es una consecuencia de la fuente, el tratamiento y la distribución del agua. Idealmente, la protección del agua potable debería centrarse en elevar la calidad del agua de origen en lugar de aumentar la sofisticación del tratamiento. El tratamiento solo no es a prueba de fallos, sino que debe utilizarse como parte de un enfoque de barrera múltiple [18], [19].

El enlace entre la calidad del agua de la fuente y la necesidad de tratamiento es reconocido por el SWDA de los Estados Unidos. Las evaluaciones han demostrado que la administración efectiva puede reducir, retrasar o evitar los costos sustanciales asociados con el tratamiento del agua más allá de la desinfección [20]. Es especialmente crítico comprender la ecología de los patógenos humanos y gestionarlos mediante la prevención de la contaminación de las fuentes de agua.

Los mayores costos de los usuarios a corto plazo para desarrollar programas de cuencas hidrográficas integradas pueden reducir tanto los riesgos como los costos de salud humana y ambiental a largo plazo. La disparidad entre las políticas que describen la protección de las cuencas hidrográficas y la capacidad de los servicios públicos de agua para implementar 
programas de cuencas hidrográficas subraya el papel fundamental del Gobierno. La política debe ir más allá de las declaraciones y proporcionar instrumentos para el logro práctico de los objetivos de la política [10].

Se debe considerar las implicaciones a corto y largo plazo de la gestión de los recursos hídricos. La prevención de la contaminación del agua parece una directiva de manejo más sabia y prudente que la limpieza de nuestras fuentes de agua en el futuro. El agua es esencial para la sostenibilidad, por lo que las políticas deben dirigirse necesariamente a gestionar y utilizar el agua de manera sostenible.

\section{REFERENCIAS}

[1] J. A. Romero, Calidad del agua, Bogotá: Escuela Colombiana de Ingeniería, 2009.

[2] J. Arboleda Valencia, Tratamiento y purificación del agua, Bogotá: Mc Graw Hill, 2000.

[3] W. J. Weber y Ja. A. Borchardt, Control de la calidad del agua: procesos fisicoquímicos, Barcelona: Reverté, 1979.

[4] R. J. Cicerone, "Safe Drinking Water Is Essential", Reports from Natl. Acad., sept., 2007. [MP4].

[5] H. B. Wright y W. L. Cairns, "Desinfeccion de agua por medio de luz ultravioleta H. B. Wright y W. L. Cairns Trojan Technologies Inc. 3020 Gore Road, London, Ontario, Canada N5V 4T7", Trojan Technol. Inc., vol. 4, pp. 1-28, 1996.

[6] R. Guimarães, J. R., Ibáñez, J., Litter, M. I. y R. Pizarro, "Desinfección de agua", en Eliminación de contaminantes por fotocatálisis heterogénea, M. A. Blesa y B. Sánchez Cabrero, eds. Madrid: CIEMAT, pp. 375-388, 2001.

[7] Massachusetts Water Resources Authority, "Water Quality Update: An Analysis of January 2018 Sampling Data”, Massachusetts , en., 2018.

[8] P. D. G. de C. y Procesos, "Productos y servicios de la EAAB 2018”, 2018.
[9] A. M. Alcocer, "Contrato de Servicios Públicos Domiciliarios de Acueducto y Alcantarillado de Bogotá. Colombia", Bogotá, 2015.

[10] One Water L.A., "Watershed Protection Program”, Los Abgeles, 2014.

[11] Massachusetts Water Resources Authority, "Massachusetts Water Resources Authority MWRA Water Supply and Treatment", Massachusetts, 2012.

[12] U.S. EPA, "Understanding the Safe Drinking Water Act”, 1974. [En línea]. Disponible en: https://www.epa.gov/sites/production/files/2015-04/documents/epa816f04030.pdf

[13] Massachusetts Department of Conservation and Recreation (DCR)., "Water Quality Report: 2010 Wachusett Reservoir and Watershed," n. ${ }^{\circ}$ abr., 2011.

[14] Boston Water and Sewer Commission, (s.f.), "About BWSC" [En línea]. Disponible en: https://www.bwsc.org/about [último acceso 26 de abril de 2019].

[15] Ministerio de Ambiente Vivienda y Desarrollo Territorial, "Reglamento Técnico del Sector de Agua Potable y Saneamiento Básico RAS-2000. Sección II. Título C. Sistemas de potabilización”, Bogotá, (nov. 2000).

[16] A. F. Topic et al., "Awwa Research Foundation, 2005” 2005.

[17] J. M. Davies y A. Mazumder, "Health and environmental policy issues in Canada: The role of watershed management in sustaining clean drinking water quality at surface sources," J. Environ. Manage., vol. 68, n. ${ }^{\circ}$ 3, pp. 273-286, 2003.

[18] L. O. Gostin, Z. Lazzarini, V. S. Neslund y M. T. Osterholm, "Water quality laws and waterborne diseases: Cryptosporidium and other emerging pathogens", Am. J. Public Health, vol. 90, n. ${ }^{\circ}$ 6, pp. 847-853, 2000.

[19] G. F. Craun, "Surface Water Supplies and Health", J Am Water Works Ass, vol. 80, n. ${ }^{\circ}$ 2, pp. 40-52, 1988.

[20] G. Chichilnisky y G. Heal, "Economic returns from the biosphere," Nature, vol. 391, pp. 629-630, 1998. 